\title{
Fiber reinforced mortars based on free Portland-CSA binders under high stress rate
}

\author{
Luigi Coppola ${ }^{1}$, Denny Coffetti $^{1}$, Elena Crotti $^{1}$, Daniele Forni ${ }^{2}$ and Ezio Cadoni $^{2}$ \\ ${ }^{1}$ University of Bergamo, Dipartimento di Ingegneria e scienze applicate, Italy \\ ${ }^{2}$ DynaMat Laboratory, University of Applied Sciences of Southern Switzerland, 6952 Canobbio, Switzerland
}

\begin{abstract}
In this paper, dynamic behaviour of fiber reinforced mortars manufactured with innovative binders based on calcium sulphoaluminate cement (CSA), supplementary cementitious materials (SCMs), gypsum $(\mathrm{G})$ and hydrated lime $(\mathrm{CH})$ was investigated. Fly ash (FA) and ground granulated blast furnace slag (GGBFS) were used to develop sustainable Portland-free cementitious materials. Polypropylene structural fibers ( $1 \%$ by mortar volume) were used to reinforce the cementitious matrix. Fresh properties of mortars were evaluated in terms of workability and specific mass. In addition, elastic modulus, compressive and flexural strength were determined up 28 days from casting. The dynamic behaviour was studied by means of Split Hopkinson Tensile bar having $60 \mathrm{~mm}$ in diameter. Preliminary dynamic results reported in terms of stress versus crack opening displacement were evaluated and discussed.
\end{abstract}

\section{Introduction}

The reduction of environmental impact of reinforced concrete structures is one of the main topic in the construction sector $[1,2]$. The total replacement of Portland cement (OPC) with alternative binders [3, 4] and the use of artificial aggregates $[5,6]$ are two possible strategies to increase sustainability of concrete. Calcium sulphoaluminate cements (CSA) combine outstanding mechanical and physical properties with a low environmental impact compared to OPC. However, CSA cement is used in ternary mixtures with OPC and gypsum (G) with OPC/CSA ratios up to 2 [7]. This leads to a slight reduction in $\mathrm{CO}_{2}$ emissions and energy production, generally close to $15-20 \%$ compared to $\mathrm{OPC} / \mathrm{CSA} / \mathrm{G}$ mortars at the same strength class. On the contrary, the total replacement in the ternary binder of OPC with supplementary cementitious materials (SCM) and hydrated lime $(\mathrm{CH})$ determines a strong reduction of environmental impact, up to $60 \%$, of $\mathrm{CSA} / \mathrm{SCM} / \mathrm{CH} / \mathrm{G}$ mixtures. Moreover, previous studies [8] have shown the excellent mechanical properties and the low shrinkage of mortars manufactured with cement-free CSA-based binders. For these reasons, these mortars are particularly suitable for the restoration and conservation of existing reinforced concrete structures. The aim of the article is to evaluate the effect of the addition of polypropylene structural fibers on the rheological, mechanical and dynamic properties of both $\mathrm{CSA} / \mathrm{OPC} / \mathrm{G}$ and $\mathrm{CSA} / \mathrm{SCM} / \mathrm{CH} / \mathrm{G}$ mortars manufactured respectively with and without Portland cement.

\section{Experimental procedure}

\subsection{Materials and mix design}

A ternary binder based on commercial CSA clinker, ordinary Portland cement CEM I 52.5R (according to EN 197-1) and gypsum in form of anhydrite (G) was used to manufacture the reference mortar. Ground granulated blast furnace slag (GGBFS, according to EN 15167-1), low calcium siliceous fly ash (FA, according to EN 450-1) and hydrated lime CL90-S class $(\mathrm{CH}$, according to EN 459-1) were employed to replace totally OPC in sustainable mortars.

Table 1. Composition of mortars. Suffix "FR" denotes the use of polypropylene fibers in cement matrix.

\begin{tabular}{|c|c|c|c|}
\hline $\begin{array}{c}\text { Composition } \\
{\left[\mathrm{kg} / \mathrm{m}^{3}\right]}\end{array}$ & REF & GGBFS & FA \\
\cline { 2 - 4 } & REF FR & GGBFS FR & FA FR \\
\hline CSA & 190 & 190 & 190 \\
\hline OPC & 190 & -- & -- \\
\hline G & 95 & 95 & 95 \\
\hline GGBFS & -- & 165 & -- \\
\hline FA & -- & -- & 165 \\
\hline CH & -- & 25 & 25 \\
\hline Sand & 1425 & 1425 & 1425 \\
\hline Water & 252 & 252 & 252 \\
\hline $\begin{array}{c}\text { Set-retarding } \\
\text { admixture }\end{array}$ & 3.8 & 3.8 & 3.8 \\
\hline \multirow{2}{*}{ Fibers } & 0 & 0 & 0 \\
\cline { 2 - 4 } & 10 & 10 & 10 \\
\hline Water/binder & 0.53 & 0.53 & 0.53 \\
\hline Sand/binder & 3.0 & 3.0 & 3.0 \\
\hline
\end{tabular}


Polypropylene structural fibers (length: $29 \mathrm{~mm}$, diameter: $0.75 \mathrm{~mm}$, aspect ratio: 37 , dosage: $1 \%$ by mortar volume) were used to reinforce the cementitious matrix. Moreover, natural siliceous sand with maximum diameter equal to $2.5 \mathrm{~mm}$ was used (sand/binders ratio equal to 3) while water/binders ratio was fixed at 0.53 . Finally, tartaric acid-based set-retarding admixture was added at $0.8 \%$ respect to binders mass in order to avoid extra-short setting time and pronounced workability loss of mortar in the plastic phase.

\subsection{Specimens}

Prismatic specimens $40 \times 40 \times 160 \mathrm{~mm}^{3}, 150 \mathrm{~mm}$ cube samples, cylindrical specimens $(100 \mathrm{~mm}$ diameter, $\mathrm{h} / \mathrm{d}=$ 2) were produced according to EN 1015-2 and cured in a climatic chamber at $20{ }^{\circ} \mathrm{C}$ and R.H. 60\%. Cylinder specimens $60 \mathrm{~mm}$ in diameter were obtained by coring in the cast direction $150 \mathrm{~mm}$ cube samples. By machining $60 \mathrm{~mm}$ long sample were then obtained. Finally, each sample was notched (notch depth $5 \mathrm{~mm}$ ) and used to study the dynamic tensile behaviour. Moreover, in order to understand the effect of cast direction on the fiber distribution, some cylinder specimen has been cored orthogonally to the cast direction.

\subsection{Fresh and hardened state tests}

Fresh and hardened state tests were performed on laboratory of Department of Engineering and Applied Sciences at University of Bergamo, Italy.

At the end of the mixing procedure, workability of mortars was measured by means of flow table according to EN 1015-3. In addition, specific mass was evaluated on fresh mortars according to EN 1015-6 standard. Specific mass, compressive and flexural strength at 1, 7 and 28 days from casting were determined according to EN 1015-11. Elastic modulus was also measured on 28day cylindrical specimens in accordance with method B, EN 12390-13.

\subsection{Setup for dynamic tests}

Preliminary dynamic tensile tests were conducted at the DynaMat laboratory of the University of Applied Sciences of Southern Switzerland by means of a modified Hopkinson bar apparatus (MHB). The mechanical properties in terms of stress-displacement relationship were evaluated imposing a displacement rate of approximately $2.7 \mathrm{~m} / \mathrm{s}$. Similar setups were recently used to perform dynamic tests of fiber reinforced cement mortars [9-11].

The used MHB setup consist of an input $(5.8 \mathrm{~m})$ and an output bar $(3 \mathrm{~m})$. The first part $(2.8 \mathrm{~m})$ of the input bar is used as pretensioned bar and is made of high strength steel and having a diameter of $12 \mathrm{~mm}$. The remaining part of the input bar as well as the output bar are made of aluminum and having a diameter of $60 \mathrm{~mm}$. A bi-component epoxy resin was used to glue the specimens to the bars. Due to the glue curing time at least 8 hours hardening time at room temperature were necessary. Moreover, no heating treatment was used to accelerate the hardening time to avoid any temperature effect on polypropilene structural fibers. The functioning of the modified Hopkinson bar setup in tension as well as the main conditions to be fulfilled have been widely discussed and reported [12-17].

In this paper the dynamic test results have been reported in terms of engineering stress versus crack opening displacement (COD).

The engineering stress, $\sigma(t)$, was evaluated on the basis of the signal recorded on the gauge placed on the output bar:

$$
\sigma(\mathrm{t})=\mathrm{E}_{0} \mathrm{~A}_{0} / \mathrm{A}_{\mathrm{S}} \varepsilon_{\mathrm{T}}(\mathrm{t})
$$

where, $\mathrm{E}_{0}$ and $\mathrm{A}_{0}$ are the modulus of elasticity and the cross-sectional area of the aluminium bars respectively, $A_{S}$ is specimen cross sectional area and $\varepsilon_{T}(t)$ is the transmitted pulse recorded on the output bar.

The crack opening displacement was directly measured following the motion of two black and white edges painted and glued between the sample notch (see Figure 1). An electro-optical extensometer $200 \mathrm{XR}$ with a measuring range of $5 \mathrm{~mm}$ (maximum resolution of $5 \cdot 10^{-4}$ $\mathrm{mm})$ and equipped by a gauge length adapter $(1-25 \mathrm{~mm})$ was used. The COD was evaluated as the difference between the target displacement recorded on the input bar (Displ. 1) and the target displacement recorded on the output bar (Displ. 2):

$$
\operatorname{COD}^{\mathrm{r}}(\mathrm{t})=\text { Displ. } 1-\text { Displ. } 2
$$

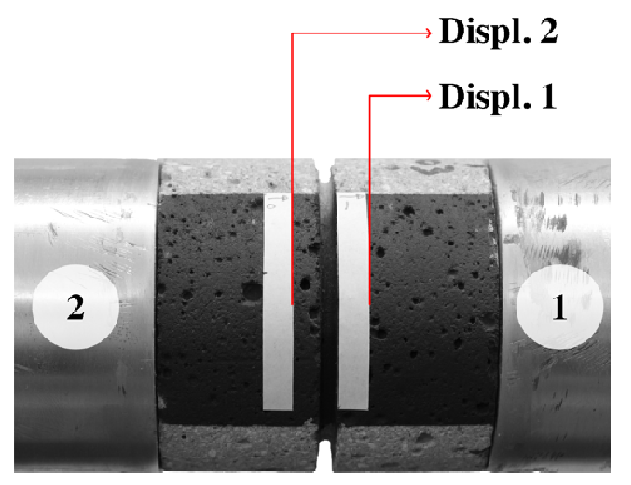

Fig. 1. Black and white targets on a $60 \mathrm{~mm}$ specimen glued between the input (1) and the output (2) bars.

For the sake of completeness, the $\operatorname{COD}^{\mathrm{r}}(\mathrm{t})$ recorded by means of the electro-optical extensometer was compared to the one obtained evaluating the displacement acting on the two faces of the specimen in contact with the input and output bars (see Figure 2):

$$
\operatorname{COD}^{\mathrm{t}}(\mathrm{t})=\mathrm{d}_{\text {inp }}-\mathrm{d}_{\text {out }}
$$

where, $d_{\text {inp }}$ is the input bar displacement and $d_{\text {out }}$ is the output bar displacement, evaluated as follow:

$$
\begin{gathered}
\mathrm{d}_{\text {inp }}=\mathrm{C}_{0} \int\left(\varepsilon_{\mathrm{I}}-\varepsilon_{\mathrm{R}}\right) \mathrm{dt} \\
\mathrm{d}_{\text {out }}=\mathrm{C}_{0} \int \varepsilon_{\mathrm{T}} \mathrm{dt}
\end{gathered}
$$


where, $\mathrm{C}_{0}$ is the elastic wave speed, $\varepsilon_{\mathrm{I}}(\mathrm{t})$ is the incident pulse, $\varepsilon_{R}(t)$ is the reflected pulse and $\varepsilon_{T}(t)$ is the transmitted pulse.

In Figure 2 the comparison between the recorded $\left(\mathrm{COD}^{\mathrm{r}}\right)$ and the evaluated $\left(\mathrm{COD}^{t}\right)$ crack opening displacements has been reported. Up to the time of failure both signals are in good agreement.

Moreover, by means of a fast recording camera MotionPro Y4-S3 each dynamic test was recorded to observe the failure process.

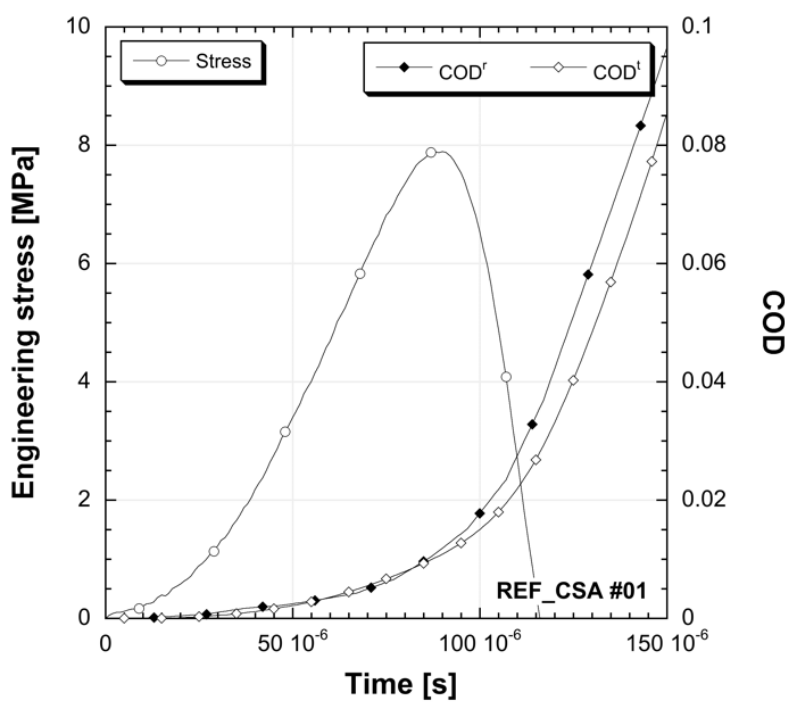

Fig. 2. Time versus CODs and engineering stress.

\section{Experimental results and discussion}

\subsection{Fresh properties \& hardened tests}

The addition of polypropylene fibers to the mixtures determines a reduction in workability equal to $10 \mathrm{~mm}$ measured on flow table, independently of binders employed. On the contrary, negligible differences were detected on specific mass between fiber reinforced and plain mortars both at fresh and hardened state. Moreover, experimental data shows a greater mass loss over time for FA- and GGBFS-based mortars respect to reference mixture, regardless of fibers.

Table 2. Workability and specific mass of mortars.

\begin{tabular}{|c|c|c|c|c|}
\hline Mixtures & $\begin{array}{c}\text { Flow } \\
{[\mathrm{mm}]}\end{array}$ & $\begin{array}{c}\text { Specific } \\
\text { mass } \\
\text { at fresh } \\
\text { state } \\
{\left[\mathrm{kg} / \mathrm{m}^{3}\right]}\end{array}$ & $\begin{array}{c}\text { Specific } \\
\text { mass } \\
\text { at fresh } \\
\text { state } \\
{\left[\mathrm{kg} / \mathrm{m}^{3}\right]}\end{array}$ & $\begin{array}{c}\text { Mass } \\
\text { loss } \\
{\left[\mathrm{kg} / \mathrm{m}^{3}\right]}\end{array}$ \\
\hline REF & 160 & 2150 & 2132 & 18 \\
\hline GGBFS & 160 & 2148 & 2053 & 95 \\
\hline FA & 180 & 2151 & 2081 & 70 \\
\hline REF FR & 150 & 2148 & 2131 & 17 \\
\hline $\begin{array}{c}\text { GGBFS } \\
\text { FR }\end{array}$ & 150 & 2147 & 2050 & 97 \\
\hline FA FR & 170 & 2149 & 2079 & 70 \\
\hline
\end{tabular}

According to Coppola et al. [8], the total substitution of Portland cement with GGBFS or FA causes a decrease in compressive and flexural strength up to $35 \%$ at the same ages. Indeed, 28-day compressive strength of mortars containing $\mathrm{CSA} / \mathrm{OPC} / \mathrm{G}$ reaches $78 \mathrm{MPa}$ while sustainable mixture manufactured with $\mathrm{SCM}$ (FA or GGBFS) in place of OPC achieve $50 \mathrm{MPa}$. Furthermore, fiber reinforced mortars are characterized by a slight reduction of mechanical properties (up to 5\%) at early and long ages respect to those exhibit by mortars manufactured without polypropylene fibers.

Elastic modulus of mortars are not affected by the presence of structural fibers. In fact, negligible differences between fiber reinforced and plain mortars were measured on cylindrical specimens. On the other hand, by replacing OPC with FA is possible to observe a reduction in Young modulus approximately equal to 2 $\mathrm{GPa}$. Finally, the use of GGBFS in place of OPC causes a reduction in the rigidity of cementitious matrix $(4 \mathrm{GPa})$ respect to reference mortars.

Table 3. Quasi-static mechanical properties of mortars.

\begin{tabular}{|c|c|c|c|c|c|c|c|}
\hline \multirow[t]{2}{*}{ Mixtures } & \multicolumn{3}{|c|}{$\begin{array}{c}\text { Compressive } \\
\text { strength } \\
{[M P a]}\end{array}$} & \multicolumn{3}{|c|}{$\begin{array}{c}\text { Flexural } \\
\text { strength } \\
{[M P a]}\end{array}$} & \multirow{2}{*}{$\begin{array}{c}\begin{array}{c}\text { Elastic } \\
\text { modulus } \\
{[G P a]} \\
28 d\end{array} \\
\end{array}$} \\
\hline & $1 d$ & $7 d$ & $28 d$ & $1 d$ & $7 d$ & $28 d$ & \\
\hline REF & 37.0 & 65.1 & 77.6 & 8.1 & 8.1 & 8.3 & 26.7 \\
\hline GGBFS & 16.7 & 44.1 & 48.9 & 5.3 & 5.8 & 6.2 & 22.9 \\
\hline FA & 15.4 & 46.9 & 49.3 & 4.7 & 5.8 & 6.1 & 24.8 \\
\hline REF FR & 32.8 & 63.4 & 75.6 & 6.2 & 8.2 & 9.2 & 26.8 \\
\hline $\begin{array}{c}\text { GGBFS } \\
\text { FR }\end{array}$ & 12.8 & 43.0 & 48.1 & 4.0 & 6.3 & 6.5 & 22.1 \\
\hline FA FR & 15.1 & 46.2 & 48.3 & 4.0 & 6.4 & 6.5 & 25.1 \\
\hline
\end{tabular}

\subsection{Dynamic tests}

Results on the dynamic behaviour of mortars manufactured with innovative binders based on calcium sulphoaluminate cement (CSA) with and without polypropilene structural fibers (1\% by mortar volume) are discussed in this section. At least three satisfactory tests were performed for each material.

Preliminary dynamic tensile test results obtained on the reference mortar $(\mathrm{CSA} / \mathrm{OPC} / \mathrm{G})$ and Portland-free cementitious material ( $\mathrm{CSA} / \mathrm{GGBFS} / \mathrm{CH} / \mathrm{G})$ have been compared. The stress versus crack opening displacement curves are depicted in Figure 3 and Figure 4. The maximum tensile strengths are reported in Table 4 .

Table 4. Maximum tensile strengths.

\begin{tabular}{|c|c|}
\hline REF & $7.31 \pm 0.83$ \\
\hline REF FR & $6.31 \pm 0.21$ \\
\hline REF FR $\perp$ & $8.61 \pm 1.12$ \\
\hline GGBFS & $6.45 \pm 1.10$ \\
\hline GGBFS FR & $5.67 \pm 1.41$ \\
\hline
\end{tabular}


It is possible to observe that addition of ground granulated blast furnace slag (Portland-free) led to a slight decrease of the maximum tensile strength in comparison to the reference mortar. This behaviour has been observed for both fiber reinforced and non-fiber reinforced mortars.

The addition of polypropilene structural fibers seems to negatively affects the mechanical behaviour of samples cored in the cast direction, leading to a reduction of the maximum tensile strength. Observing the surface failure of these samples it is possible to observe a fiber orientation which is nearly perpendicular to the tensile load. Furthermore, samples cored perpendicular to the cast direction highlighted a different behaviour. An increase of the maximum tensile strength is noted for the fiber reinforced reference samples (REF FR $\perp$ ). The surface failure of these samples shows a better fiber orientation (Figure 5), which is nearly parallel to the tensile load. As a consequence, a little post-peak behaviour is observed (Figure 3).

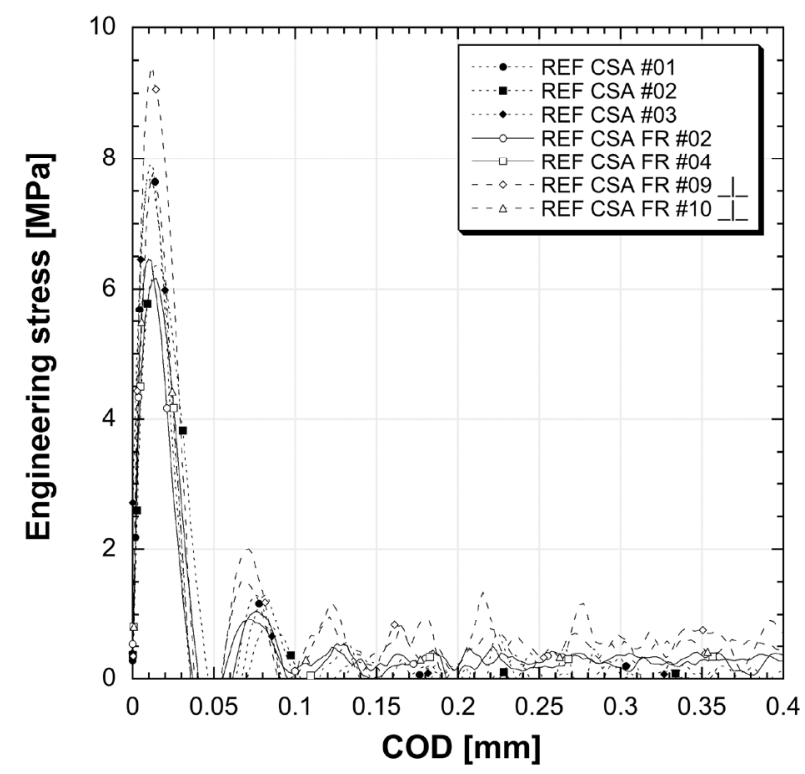

Fig. 3. Engineering versus $\mathrm{COD}$ behaviour of the reference calcium sulphoaluminate mortar.

\section{Conclusions}

The paper is aimed to the preliminary evaluation of rheological, mechanical and dynamic properties of fiber reinforced CSA-based mortars in which OPC is totally replaced by supplementary cementitious materials and hydrated lime. The use of polypropylene fibers causes a reduction in workability equal to $10 \mathrm{~mm}$ spreading at equal mixing water dosage, regardless of binders employed. Moreover, fiber reinforced mortars are characterized by a slight reduction of mechanical properties (up to $5 \%$ ) at early and long ages respect to those exhibit by mortars manufactured without polypropylene fibers. On the contrary, elastic modulus of mortars are not affected by the presence of structural fibers. The tensile behaviour of mortars manufactured with innovative binders based on calcium sulphoaluminate cement (CSA) was preliminary investigated in dynamic conditions by imposing a displacement rate of approximately $2.7 \mathrm{~m} / \mathrm{s}$. It was found that the addition of ground granulated blast furnace slag (Portland-free) led to a slight decrease of the maximum tensile strength. Moreover, a brittle behaviour (absence of post-peak) has been observed for both fiber reinforced and non-fiber reinforced samples cored in the cast direction, in which the softening branch is practically the same. In addition, samples cored orthogonally from the cast direction showed higher values of the maximum tensile strength and a post-peak behaviour characterised by a stress plateau of approximately $0.5 \mathrm{MPa}$ up to a COD of about $2 \mathrm{~mm}$.

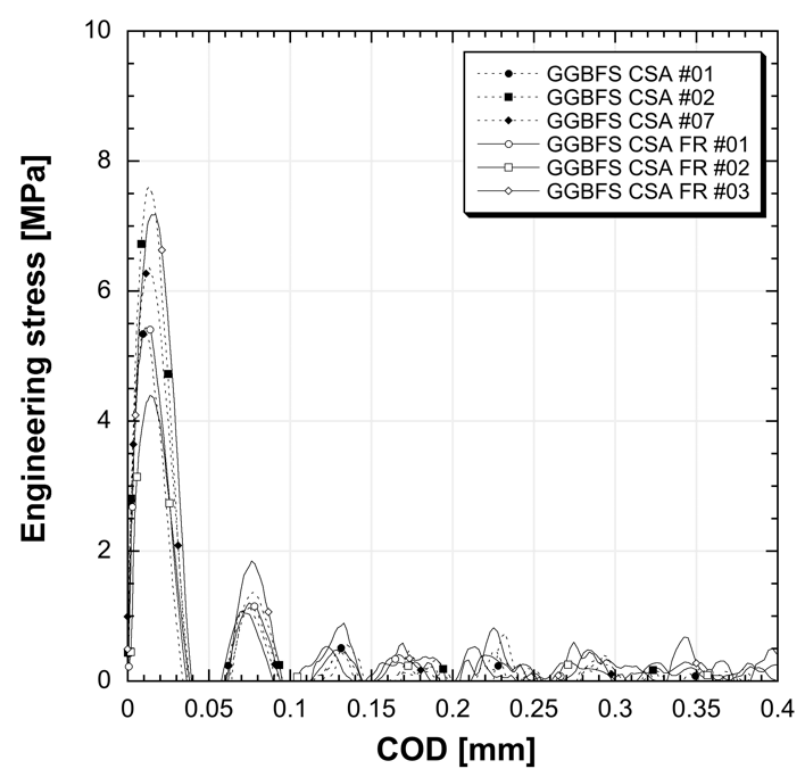

Fig. 4. Engineering versus COD behaviour of the ground granulated blast furnace slag mortar.

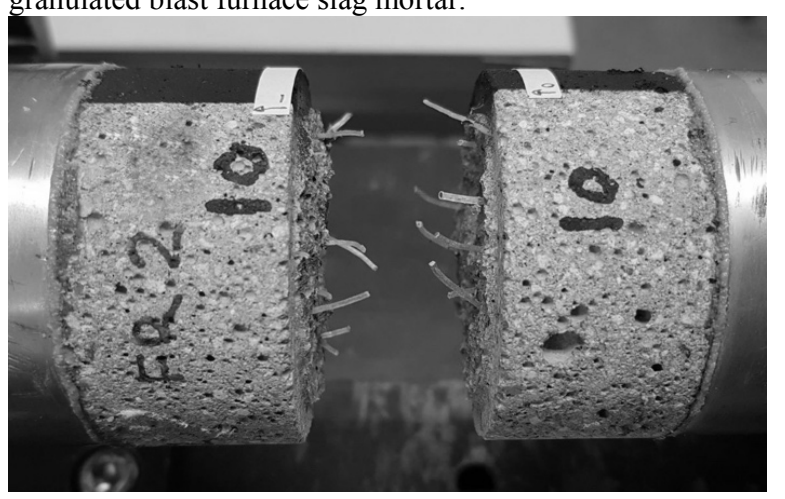

Fig. 5. Picture of a sample cored orthogonally from the cast direction and after a dynamic tensile test (REF CSA FR \#10).

\section{References}

1. FA. Rodrigues, I. Joekers, Env. Chem. Lett. 9, 151166 (2011)

2. C. Meyer, Cem. Concr. Comp. 31(8), 601-605 (2009)

3. C. Shi, AF. Jimènez, A. Palomo, Cem. Concr. Res. 41(7), 750-763 (2011)

4. MCG. Juenger, F. Winnefeld, JL. Provis, JH. Ideker, 
Cem. Concr. Res. 41(12), 1232-1243 (2011)

5. L. Coppola, A. Buoso, D. Coffetti, P. Kara, S. Lorenzi, Constr. Build. Mater. 123, 115-119 (2016)

6. L. Coppola, P. Kara, S. Lorenzi, Mater. Constr. 66(324), e101 (2016)

7. M. Marroccoli, F. Montagnaro, A. Telesca, GL. Valenti, 2nd Int. Conf. Sustain. Constr. Mater. Technol. 625-635 (2010)

8. L. Coppola, D. Coffetti, S. Lorenzi, 10th Int. Conf. Cem. Mater. Alter. Bind. Sust. Constr. (2017)

9. L. Kruszka, W. Moćko, L. Fenu, E. Cadoni, EPJ Web Conf 945008 (2015)

10. L. Fenu, D. Forni, E. Cadoni, Comp. Part B: Engg 92(5) 142 - 150 (2016)
11. L. Coppola, E. Cadoni, D. Forni, A. Buoso, Appl. Mech. Mat. 82, 190-195 (2011)

12. E. Cadoni, D. Forni, EPJ-ST 225(2), 253-264 (2016)

13. D. Asprone, E. Cadoni, A. Prota , G. Manfredi, ASCE J. Comp. Constr. 13(6), 558-564 (2009)

14. I. Curosu, V. Mechtcherine, D. Forni, E. Cadoni, Cem Concr Res 10216 - 28 (2017)

15. E. Cadoni, C. Albertini, G. Solomos, J. de Phys. IV 134, 647-652 (2006)

16. E. Cadoni, G. Solomos, C. Albertini, Mag. Concr. Res. 61(3), 221-230 (2009)

17. E. Cadoni, G. Solomos, C. Albertini, Mag. Conc. Res. 65(11), 660-672 (2013) 
